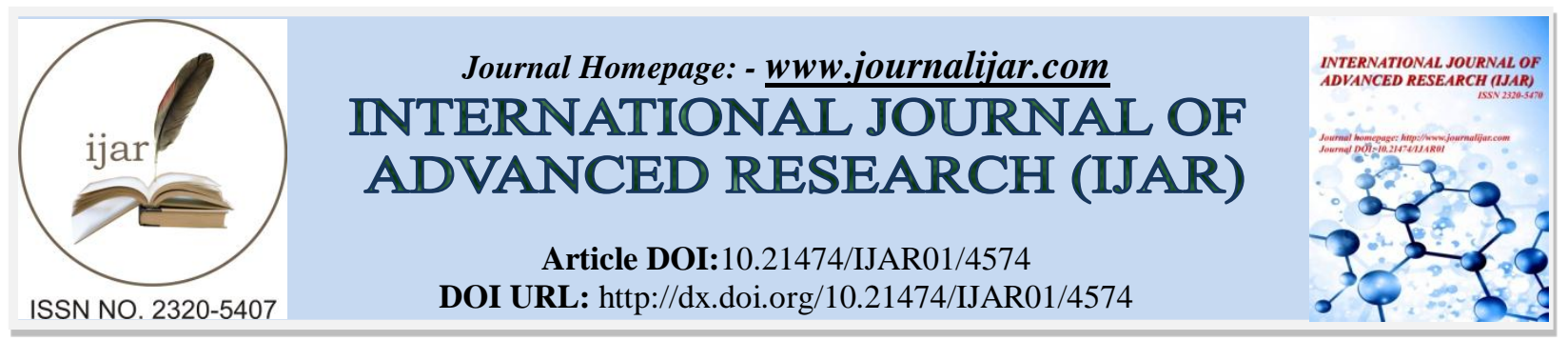

RESEARCH ARTICLE

\title{
A COMPARITIVE STUDY ON NUTRITIONAL, PHYSICAL AND COGNITIVE DEVELOPMENT OF PRE-SCHOOL CHILDREN RESIDING AT HOME AND AT DAYCARE CENTRE.
}

Nishu Gupta and Dr. Divya Sanghi.

Department of Nutrition and Dietetics, Faculty of Applied Sciences, Manav Rachna International University, Faridabad.

\section{Manuscript Info}

......................

\section{Manuscript History}

Received: 22 April 2017

Final Accepted: 24 May 2017

Published: June 2017

\section{Abstract}

Background: During childhood, adequate nutrition is essential to remain healthy and to ensure that our body functions properly. Therefore, for children of this age (2-5yrs), adequate amount of all essential nutrients need to be provided through the diet for maintaining their physical and mental health. Various factors which affect our body needs for different nutrients include age, gender, activity as well as the body weight, height.

Aim: The present study aimed to compare nutritional profile, cognitive development and physical growth among day care (DC) and home residing children (HR).

Methodology: Present study recruited 40 subjects; 20 were from day care and 20 from home residing. A pretested questionnaire was used for data collection. In Anthropometry, z-score was calculated by standard growth charts (Height-weight), nutrient intake was assessed by 24 hrs- dietary recall and cognitive development was analyses by pretested questionnaire (10 items).

Result: Both groups (DC and HR) were age-sex matched. Z-score distribution in both groups was insignificant different as DC group had 55\% normal growth whereas HR had $40 \%$ normal growth and very few comes under obese (35\% and 50\%) and underweight (10\%) in both groups respectively. Cognitive score distribution in both groups was also insignificant HR group had $85 \%$ children who were having excellent cognitive development scores whereas $60 \%$ in DC. The nutrient intake of both groups was significantly different. Conclusion: The study shows that DC had better nutritional intake as compared to HR group whereas HR group had better cognitive score as compared to DC group. And there was no significant difference in physical profiles of both groups. The cognitive development of children is not only affected by nutrition, it is also affected by other factors like environment, breast feeding etc.

Copy Right, IJAR, 2017,. All rights reserved.

\section{Introduction:-}

Infancy is a period of rapid growth. During the first year of life, the infant grows and develops far more rapidly than at any other time in life. This is evident from the fact that the newborns are completely dependent on the mother or 
the caretaker, develops a fair degree of physical and mental abilities by the first year. The child developed the ability of speech and is able to express himself. He attains a fairly good motor development and starts walking and holds objects. By this time he also develops a strong emotional and psychological relationship with his near and dear ones ${ }^{1}$.

Cognitive development is a term that covers human perception, thinking, and learning. Nutrition, genes, and environment are three major factors impacting cognitive development. However, the role of good nutrition in child development and learning is important. Nutrition during the early years of a child's life is linked to performance in later years. Many research studies focus on the relationships between breakfast and learning in school-age children; other researchers identified the importance of nutrition at earlier ages. The effect of nutrition on the brain begins before birth - with the nutrition of the mother. Under nutrition resulting negative effects on brain development during pregnancy and the first two years of life may be permanent and irreversible. Breast-feeding appears to lead to higher IQ/cognitive development. Iron is a necessary part of brain tissue. Iron deficiency during the first two years of a child's life is associated with behaviour changes and delayed psychomotor development. Iodine deficiency during early years is associated with reduced cognition and achievement in school-age children. Poorly nourished children have more problems fighting infections. Therefore, they may be sick more often, miss more school, and fail to keep up with classmates. School-age children who ate breakfast did better on performance tests than children with no breakfast ${ }^{2}$.

Day care centre is defined as care for children that take place in a care centre setting, provided by trained or untrained caregivers $^{3}$. The nutritional profile might be different for day care and home residing centres, which can affect their cognitive development. With the above background present study was carried out with the aim to compare nutritional profile, cognitive development and physical growth among day care (DC) and home residing children (HR).

\section{Designs and Methods:-}

The study was conducted in Delhi and Faridabad in January 2017. Total 40 subjects were recruited of the age 2-5 years. The Inclusion criteria of the study was 1) age should be 2-5 years, 2) willing to participate in the study and 3) should not be suffering with any chronic disease ${ }^{4}$. A pretested questionnaire was used for data collection. In Anthropometry, z-score was calculated by standard growth charts (Height-weight), nutrient intake was assessed by $24 \mathrm{hrs}$ - dietary recall and cognitive development was analyses by pretested questionnaire (10 items). Statistically analysis was done by using software SPSS 20 version.

\section{Result and Discussion:-}

Present study enrolled total 40 children from different location of Delhi- NCR. Out of 40 children $50 \%$ were belong to day care $(n=20)$, and $50 \%$ were home residing $(n=20)$.

Table 1:- Demographic data of both groups

\begin{tabular}{|l|l|l|l|}
\hline \multicolumn{1}{|c|}{ Parameters } & \multicolumn{1}{c|}{ DC group $(\mathbf{n}=\mathbf{2 0})$} & \multicolumn{1}{c|}{ HR group $(\mathbf{n}=\mathbf{2 0})$} & p-value* \\
\hline Age & $44.30 \pm 10.19$ & $48.20 \pm 12.65$ & 0.29 \\
\hline Sex, M:F (\%) & $9(45 \%): 11(55 \%)$ & $11(55 \%): 9(45 \%)$ & 0.37 \\
\hline
\end{tabular}

*Statistical analysis performed-age- student ' $\mathrm{t}$ ' test, sex- chi-square test

Demographic data of all the study subjects were depicted in Table 1. The mean age both the group was not significantly different between both groups $(\mathrm{p}=0.29)$. Similarly, gender distribution in both groups was insignificant.

Table 2:- Anthropometric measurements of both groups

\begin{tabular}{|c|c|c|c|}
\hline $\begin{array}{c}\text { Anthropometric } \\
\text { measurement }\end{array}$ & DC group (n=20) & HR group (n=20) & p-value* \\
\hline z-score & $0.50 \pm 1.27$ & $0.90 \pm 1.48$ & 0.36 \\
\hline Below -3 & $0(0 \%)$ & $0(0 \%)$ & 0.46 \\
\hline Below -2 & $2(10 \%)$ & $8(10 \%)$ \\
\hline $\mathbf{1 , 0 , - 1}$ & $11(55 \%)$ & $8(40 \%)$ \\
\hline Above 2 & $7(35 \%)$ & $2(10 \%)$ \\
\hline Above 3 & $0(0 \%)$ & \\
\hline
\end{tabular}


The mean Z-score of DC group was $0.50 \pm 1.27$ and HR group was $0.90 \pm 1.48$, (p-value $=0.36$ ) which was insignificant. On statistical analysis of distribution of Z-score in both groups was insignificant as DC group had 55\% normal growth whereas HR group had $40 \%$ normal growth and very few comes under obese (35\% and 50\%) and underweight (10\% and $10 \%$ ) in both groups respectively (Table 2). Alshammariet al (2017) conducted a study on growth profile using z-scores and observed a contrast results from present study, the prevalence of $4.73 \%$ moderate and $1.54 \%$ severe underweight; $6.65 \%$ moderate and $2.59 \%$ severe stunting; $6.34 \%$ moderate and $2.55 \%$ severe wasting was present in the study population ${ }^{4}$.

Table 3:- Cognitive development score of both groups

\begin{tabular}{|c|c|c|c|}
\hline Cognitive development & DC group $(n=20)$ & HR group $(n=20)$ & p-value* \\
\hline Total score & $7.35 \pm 1.98$ & $8.05 \pm 1.53$ & 0.22 \\
\hline$\geq 3$ (poor) & $1(5 \%)$ & $1(5 \%)$ & \multirow[t]{4}{*}{0.30} \\
\hline$\geq 5$ (average) & $3(15 \%)$ & $1(5 \%)$ & \\
\hline$\geq 7($ good $)$ & $4(20 \%)$ & $1(5 \%)$ & \\
\hline$<7($ excellent $)$ & $12(60 \%)$ & $17(85 \%)$ & \\
\hline
\end{tabular}

The mean cognitive development of day care group was $7.35 \pm 1.98$ and home residing group was $8.05 \pm 1.53$, with the pvalue 0.22 , which was insignificant (Table 3). On distribution of study subjects according to cognitive development scores, HR group had more children who came into excellent cognitive development category $(85 \%)$ whereas only $60 \%$ DC children were belong to excellent category, but it was statistically insignificant. In this meta-analysis of 75 studies on more than 3,888 children in 19 different countries, the intellectual development of children living in orphanages was compared with that of children living with their families. Children growing up in orphanages showed lower IQ's than did children growing up in a family. Children growing up in orphanages show a substantial lower level of IQ (average IQ of 84 ) than their peers reared in (foster) families (average IQ of 104), and the difference amounted to 20 IQ points ${ }^{5}$.

Table 4:- Dietary intake of both groups

\begin{tabular}{|c|c|c|c|}
\hline Nutritional data & DC group $(\mathbf{n = 2 0})$ & HR group $(\mathbf{n = 2 0})$ & p-value* \\
\hline Energy & $1329.10 \pm 205.20$ & $1003.41 \pm 183.34$ & 0.000 \\
\hline Protein & $41.05 \pm 6.74$ & $30.04 \pm 6.53$ & 0.000 \\
\hline Fat & $54.16 \pm 9.15$ & $45.04 \pm 9.58$ & 0.004 \\
\hline Iron & $7.25 \pm 1.36$ & $5.56 \pm 0.91$ & 0.000 \\
\hline Calcium & $1211.82 \pm 285.77$ & $844.14 \pm 378.20$ & 0.001 \\
\hline Vitamin A & $2301.34 \pm 1216.44$ & $1044.84 \pm 560.43$ & 0.000 \\
\hline
\end{tabular}

*Statistical analysis performed-dietary intake- student ' $t$ ' test

The mean value of protein was $41.05 \pm 6.74$ and $30.04 \pm 6.53$, fat $-54.16 \pm 9.15$ and $45.04 \pm 9.58$, iron- $7.25 \pm 1.36$ and 5.56 \pm 0.91 , calcium-1211.82 \pm 285.77 and $844.14 \pm 378.20$, and vitamin A- $2301.34 \pm 1216.44$ and $1044.84 \pm 560.43$ respectively. On comparison of all the nutrients in both the group was statically significant (p- value $<0.05$ ) as DC group had higher intake of nutrients in comparison to HR group (Table 4).Steyn et al.showed that nutrients which had an average NAR of at least $100 \%$ were protein, zinc, vitamin B12, vitamin C, riboflavin and thiamine. Those with an average NAR greater than or equal to $90 \%$ were energy, iron, vitamin A and vitamin B6. The average NARs for calcium and folate were too low, being less than $56 \%$ for calcium and less than $65 \%$ for folate. This is contrast to present study findings as no nutrient intake as per the $\mathrm{RDA}^{6}$.

\section{Bibliography:-}

1. Khanna K, Ph. D, Textbook of Nutrition and Dietetics, Second Edition, 99.

2. National Food Service Management resource guide. National Food Service Management Institute, The University of Mississippi 2010.

3. Encyclopaedia of children's health. www.healthofchildren.com

4. Alshammari E, Suneetha E, Adnan M, Khan S, and Alazzeh A. Growth Profile and Its Association with Nutrient Intake and Dietary Patterns among Children and Adolescents in Hail Region of Saudi Arabia. 2017 (2017), 9.

5. Goswami, U. Children's Cognitive Development and Learning. York: Cambridge Primary Review Trust 2015.

6. Steyn N, Nel J, Nantel G, Kennedy G, Labadarios G. Food variety and diversity scores in children: are they good indicators of dietary adequacy. Public Health Nutr 2006 ;9(5): 644-50. 